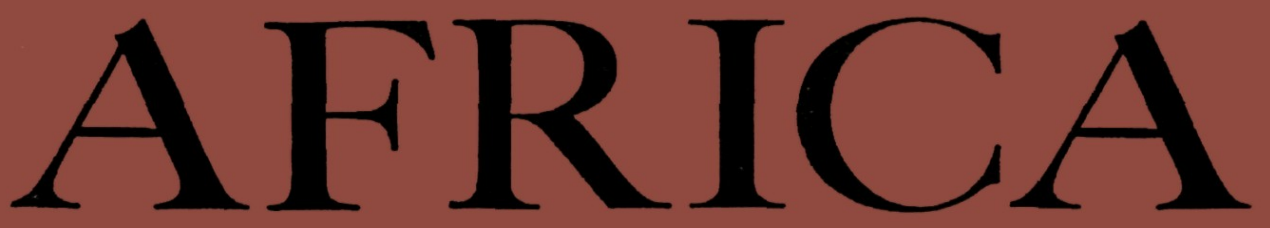

\title{
JOLRNAL OF THE
}

INTERNATIONAL AFRICAN INSTITUTE

$$
\begin{gathered}
\text { JOURNAL DE } \\
\text { L'INSTITUT INTERNATIONAL AFRICAIN } \\
\text { ZEITSCHRIFT DES }
\end{gathered}
$$

INTERNATIONALEN AFRIKANISCHEN INSTITUTS

\author{
Editor \\ DARYLL FORDE \\ Assistant Editor \\ BARBARA PYM
}

\section{LONDON \\ OXFORD UNIVERSITY PRESS}

Issued quarterly

Price I ss. net 